(2) Open Access Full Text Article

REVIEW

\title{
Regeneration of trabecular meshwork in primary open angle glaucoma by stem cell therapy: a new treatment approach
}

This article was published in the following Dove Medical Press journal:

Transplant Research and Risk Management

\section{Enzo Maria Vingolo \\ Ayoub Chabib \\ Federico Anselmucci}

Department of Sense Organs, U.O.C. Ophthalmology, Sapienza University of Rome, Latina, Italy
Correspondence: Enzo Maria Vingolo A. Fiorini Hospital, Via Firenze I, Terracina (LT) 04019, Italy

Tel +39348650 0312

Email enzomaria.vingolo@uniromal.it

\begin{abstract}
Primary open angle glaucoma (POAG) is a worldwide disease with IOP being an important risk factor for the disease. Pharmacological and surgical treatments have been mainly targeted on lowering IOP by decreasing aqueous humor production or increasing aqueous humor outflow. Stem cell therapies may open new frontiers in regenerative ophthalmology branch. In POAG there is a strong association with pathologic degeneration of the trabecular meshwork (TM) and regenerative cell-therapy approaches have been focused mainly on modulation of the degeneration. Many different adult stem cell types have been discovered in different parts of the eye such as the corneal endothelium (CE) and anterior non-filtering portion of the TM called Schwalbe's ring region. These stem cells may supply new cells for the TM and may regenerate the TM structure thus reducing IOP and restore the homeostatic function of the eye. In this paper, we report the studies' latest findings and present our perspective on approaches that seem promising in the management of POAG.
\end{abstract}

Keywords: glaucoma, trabecular meshwork, stem cell therapy, POAG, iPSC

\section{Introduction}

Glaucoma is one of the most common causes of irreversible vision loss and blindness worldwide; 60 million suffer from this disease and of these, 7 million are blind. By definition, all glaucoma involves some degree of vision loss, which is because of the death of retinal ganglion cells (RGCs), as well as degeneration of the optic nerve head, the optic nerve, and the lateral geniculate nucleus. Primary open angle glaucoma (POAG) represents about $90 \%$ of all forms of glaucoma. POAG is characterized by a painless condition of IOP elevation with a normal-appearing anterior chamber angle. The IOP elevation is an important risk factor for the disease. ${ }^{1,2}$ Many RGCs, which are the projection neurons that carry signals from retina to brain, are irreversibly lost and by the time vision loss is detected. The IOP is the result of the balance between aqueous humor production by the ciliary body and the ability of the ocular outflow pathways to remove this fluid. IOP is determined by the continuous generation of aqueous humor by the ciliary processes (inflow) and its elimination by the trabecular meshwork (TM) which together with Schlemm's canal, collector channels, and aqueous veins, constitute the major outflow pathways in the eye. TM and the endothelium of Schlemm's canal are crucial to provide resistance to the aqueous humor outflow and thus control IOP levels., ${ }^{3,4}$

The current treatment of glaucoma is based on IOP lowering by pharmacological reduction of aqueous humor production or by laser-based and other surgical procedures 
which provide an aqueous humor outflow bypass. ${ }^{5}$ An alternative or complementary strategy is to target TM to increase outflow by pharmacological agents. To this aim, many drugs are being developed and have shown encouraging results in clinical trials. Among these there are rho kinase (ROCK) inhibitors whose activity increases actomyosin contraction in smooth muscle cells, including the smooth muscle-like cells of the TM. Also, adenosine agonists can trigger a potentially important modulation of outflow resistance in vivo, particularly the interaction with $\mathrm{A} 1$ and $\mathrm{A} 2$ adenosine receptors. In the end, statins, more specifically lovastatin, can act as an important pharmacological suppressor of SPARC (secreted protein acidic and rich in cysteine) expressed in TM cells, that can provide further insight into the molecular mechanisms mediating statin enhancement of aqueous outflow facility. ${ }^{6-9}$

Understanding the fundamental mechanisms leading to dysfunction and loss of TM cells in the glaucomatous eye may be useful for developing new strategies to target this primary pathological site. ${ }^{10}$

The regenerative approach can give hope for numerous ocular pathologies, such as diabetic retinopathy and glaucoma. ${ }^{11}$

\section{Stem cell overview}

Stem cells can be categorized into embryonic stem (ES) cells, induced pluripotent stem cells (iPSCs), and adult stem cells.

iPSCs have rapidly obtained significance since their discovery by Takahashi and Yamanaka. ${ }^{12}$ One advantage of iPSCs is that these cells can be derived from readily available cell types of the intended recipient, thereby enabling autologous transplantation and avoiding immune rejection in the recipient. iPSCs present an advantage inasmuch as an autologous approach may be possible, circumventing the ethical and immunological disadvantages associated with ES cells therapy. However, there are safety concerns that involvement of retroviral vector integration for reprogramming iPSCs may cause oncogenesis. ${ }^{12-15}$

It was demonstrated that transplantation of these cells into eyes of mice promotes aqueous humor outflow, lowers IOP, and prevents RGC loss. The improvement of aqueous humor outflow dynamics in iPSC-TM recipients is accompanied by a significant increase in TM cell density in vivo. ${ }^{16}$

Considerable progress has also been made in developing human Tenon's fibroblasts as feeder cells for culturing human stem cells. ${ }^{17,18}$

\section{Structure, function, and embryology of TM}

The anterior chamber of the eye is bordered by the corneal endothelium (CE) in the front and the iris in the back. TM, scleral spur, ciliary body, and iris root, which form the anterior chamber angle are positioned at the periphery of the chamber.

TM stem cells located in the anterior chamber angle between the cornea and the iris, in the transition zone between the periphery of the CE and the anterior extension of TM, which is known as the Schwalbe's ring region.

The TM can be anatomically divided into 3 regions (from inner to outermost). The uveal meshwork is the closest to the anterior chamber and consists of a network of collagen and elastin lamellae covered by TM cells with large spaces between lamellae. The corneoscleral meshwork, which is the middle layer, is composed of a series of perforated collagen and elastin plates covered by TM cells. The most external layer, the juxtacanalicular connective tissue is a loose connective tissue containing TM cells surrounded by extracellular matrix (ECM). These 3 layers are considered part of the "filtering" TM. A fourth region of the TM is considered "non-filtering" since it resides just below Schwalbe's line. Data suggest that this region contains a population of TM stem cells. ${ }^{19,20}$

The development of the cornea begins at approximately 33 days of post fertilization. ${ }^{21}$ The primitive TM is formed at around the fourth month. It is formed from the first wave of neural crest which originated from mesenchymal cells migration between the surface ectoderm and the lens. It consists of a triangular mass of undifferentiated mesenchymal cells. During the seventh month, these cells flatten and become slightly separated from each other, and these cavities are filled with extracellular fibers. The fibers are then organized to form the trabecular lamellae. Some cells with a stellate phenotype form the juxtacanalicular layer of the TM. The complete morphogenesis of TM is completed around birth. ${ }^{20-23}$

Specific gene regulatory networks are involved in tissue developments and these include many transcription factors and molecular signals such as PITX2, PITX3, PAX6, FOXC1, FOXE3, LMX1B, and MAF. PAX6 appears to be the most important eye development regulator in a number of organisms..$^{22,24,25}$

A number of studies have noted that TM was abnormally formed in Pitx2 $2^{-/-}$and Foxc $1^{-/-}$mice. ${ }^{26-29}$ The LMX1B gene was shown to have a direct link to the dysgenesis of the TM. ${ }^{30}$ Absent or hypoplastic TM and Schlemm's canal, and profound ECM deficiencies in TM have been associated with heterozygous deficiency of BMP4. ${ }^{31}$

\section{Functions and biological features of TM cells}

TM cells are the primary cell type that occupies and forms the proximal portion of the conventional outflow pathway, 
the primary egress route for aqueous humor from the eye. To assure the effective outflow resistance regulation, the TM tissue has an important function of biological filter self-cleaning by an activity of intercepting cellular debris and reactive oxygen species (ROS). Thus, TM cells have a macrophage-like activity to clear the cellular debris derived from shade pigmented epithelia. The integrity of these cells is important for the regulation of this passageway for the maintenance of homeostatic IOP. The dysfunction of these cells may generate an extra resistance that causes an IOP elevation. TM cells create a link through cytoplasmic extensions between the intertrabecular spaces while desmosomes create a firm connection with the adjacent cells. ${ }^{32}$ Electron microscopic observations have revealed that gap junctions constitute the main intercellular bridge between TM cells.

TM cells express a variety of proteins, receptors and abilities. Among the proteins and receptors expressed there are vimentin, non-muscle actin, aquaporin-1, acetylated and acetoacetylated low-density lipoproteins, and the alpha-2 adrenergic receptor. Moreover, the expression of myocilin by TM cells increases after dexamethasone treatment. The myocilin expression in the TM cells has been suggested to play an important role in glucocorticoid-induced ocular hypertension. ${ }^{33-35}$ Among the agents able to modify the activity of cells there are fibroblast growth factor and Hepatocyte growth factor that cause TM cells mitosis in a dose-dependent way. ${ }^{36-38}$ Platelet-derived growth factor can also increase cells division in TM. Besides, it enhances the phagocytic activity and promotes ECM secretion. ${ }^{39}$ On the contrary, vascular endothelial cell growth factor can inhibit TM cells growth. ${ }^{40}$

TM cells have the ability to phagocytize and this ability probably may help to eliminate debris from aqueous humor. This characteristic demonstrates that TM is not a simple passive filter. ${ }^{41}$ In addition TM cells are contact inhibited in culture: when the cells were in contact they formed gap junctions that caused a decrease of division rate. TM cells have also contractile capability thanks to cytoplasm's contractile filaments. ${ }^{42}$

\section{TM cells loss and glaucoma}

It is important to highlight that the number of TM cells decrease with age and a decrease is also associated with glaucoma. There is also evidence of accumulation of ECM associated with alteration of gap junction between cells of the TM and Schlemm's canal, leading to TM cell death and IOP elevation. Moreover, aged and glaucomatous TM cells present damages probably caused by ROS. ${ }^{43,44}$
Alvarado et al reported a cell loss rate of $0.58 \%$ per year. ${ }^{45}$ This loss is similar to that observed in the CE. It was calculated that there were 750,000 cells in the TM of 20 year old people and around 400,000 in 80 year old people. ${ }^{46}$ There are other age-related modifications such as TM thickening, trabecular fusions, and alterations of the ECM in the juxtacanalicular TM. All these changes would lead to an increase of the aqueous outflow resistance and subsequently to IOP increases. The main risk factor in POAG is the pathological elevation of the IOP. The age-related changes are intimately linked to the glaucomatous modifications observed in POAG patients. It has been noticed that glaucomatous eyes have significantly more cellular loss than age-matched normal eyes. ${ }^{47}$ This probably causes a diminished ability to drain humor aqueous. Progressive cell loss leads to a TM thickening and fusion probably due to adhesions of the naked portions of the trabeculae. Some studies have documented accumulation of ECM and meshwork cell hyperplasia in glaucomatous TM that creates an obstruction of the outflow pathway. Consequently, TM cells are fundamental to maintain a healthy meshwork that guarantees an appropriate aqueous drainage.

\section{Evidence of therapeutic implications for TM stem-cells}

In 1982, a population of unusual cells was identified by Raviola in the region located just beneath the Schwalbe's line in rhesus monkeys. These cells have been called the Schwalbe's line cells. ${ }^{48}$

Subsequently, it was noted that there is an increased TM cell division localized in the anterior non-filtering portion of the TM after argon laser trabeculoplasty (ALT). ${ }^{49}$ It is not exactly known how this treatment is able to lower IOP; probably, the repopulation of TM, stimulated by cell division, is the main mechanism of action. ${ }^{50}$ Furthermore, there is evidence that more than $60 \%$ of cell division is initially located in the anterior non-filtering region of TM; those cells move to the burnt lesion to repopulate. It seems that these cells are probably stem cells that after ALT laser get stimulated to repopulate TM, probably through the mediation of growth factors and cytokines. Kelley et al have named them the "TM insert cells" as they are located in the insertion region into the cornea just beneath Schwalbe's line. ${ }^{51}$

Gonzalez et al found cultured TM cells capable of forming free-floating neurospheres, a function associated with neural stem cells. When the TM free-floating spheres were incubated with serum, they evolved into monolayers of cells morphologically indistinguishable from typically cultured 
TM cells, indicating the possibility that they might differentiate spontaneously into TM cells. ${ }^{52}$

As previously stated, the number of TM cells decreases significantly in the patient with glaucoma, thus depressing the aqueous outflow. It is well documented that in the transition area between the periphery of the CE and the anterior non-filtering portion of TM there is a population of stem-like cells. Thus, using the stem cells to repopulate TM may be useful to enhance drainage in glaucoma.

Stem cell therapy potentially can restore TM function and protect the optic nerve from further damage. ${ }^{53}$ Replacing glaucoma-damaged TM cells with healthy stem cells may restore the micro environment of filtering structures, and this could create a reparative proliferation and restore the physiological aqueous outflow causing a reduction in IOP thanks to the TM cells property. TM stem cells were also observed in the region where the TM inserts and have been isolated by side-population cell sorting, clonal culture, and sphere culture (Table 1). ${ }^{51,52}$ Du et al have described the isolation and characterization of a population of stem cells from human TM that in culture present a homogeneous population displaying antigenic markers previously characterized for mesenchymal stem cells and expressing gene products associated with pluripotent stem cells. These cells are capable of differentiating into TM cells with phagocytic function and expressing TM markers. All these support the hypotheses that these cells represent a resident population of adult stem cells in the human TM. Moreover, those cells are multipotent and differentiate into TM cells in vitro and in vivo, they settle in the TM region and can regenerate the TM structure thus reducing IOP in mouse models, thanks to specific TM cells properties as phagocytosis activity. ${ }^{54,55}$ As we have shown previously Zhu et al demonstrate that iPSC can be induced to differentiate into a cell type (iPSC-TM) that strongly resembles TM morphologically, compositionally express a large number of proteins characteristic of TM, and functionally respond to various stimuli in a manner typical of TM cells. For example, iPSC-TM responds to exposure to glucocorticoids with enhanced synthesis and secretion of myocilin. For this purpose mouse's iPSC-TM cells were induced from iPSC derived from fibroblasts isolated from transgenic animals; subsequently iPSCs were seeded and induced to differentiate by maintaining them in biopsy media previously conditioned by primary human TM cells. Finally, iPSC-TM cells were purified by removing cells still expressing markers of pluripotency from the iPSC-TM population to avoid tumor formation after transplantation. Therefore, 50,000 purified iPSC-TM cells were injected into the anterior chamber of mice that constitutively express human myocilin harboring a pathogenic mutation. The data demonstrate that intraocular injection of iPSC-TM prevents IOP elevation and aqueous humor outflow reduction and results in preservation of RGC density in treated mice. iPSC-TM cells have been observed to be able to restore homeostatic function in glaucoma mouse in vivo models. ${ }^{16,56}$ Moreover, Abu-Hassan et al observed that iPSC-TM cells can restore IOP homeostatic function in a human anterior segment ex vivo model. This remains the only study performed on human tissue, as shown in Table 2. In this case, human anterior segments were perfused for 48 hours to establish baseline flow and then treated with saponin for 7 minutes to remove approximately $1 / 3$ of the TM cells. The anterior segments exposed to saponin lost the ability to adjust the outflow resistance when subjected to a pressure challenge; this capability was regained when

Table I Trabecular meshwork stem cells (TMSCs)

\begin{tabular}{|l|l|l|l|l|}
\hline Authors & Year & Cells & Donor & Vitro/vivo/ex-vivo \\
\hline Acott, Samples, Bradley, Bacon, Bylsma, Van Buskirk & 1989 & TMSCs & Human & Vitro \\
\hline Gonzalez, Epstein, Luna, Liton & 2005 & TMSCs & Human & Vitro \\
\hline Du, Roh, Mann, Funderburgh, Funderburgh, Schuman & 2012 & TMSCs & Human & Vitro \\
\hline
\end{tabular}

Table 2 Trabecular meshwork stem cells (TMSCs); induced pluripotent stem cell-trabecular meshwork (iPSC-TM)

\begin{tabular}{|l|l|l|l|l|l|l|l|}
\hline Authors & Year & $\begin{array}{l}\text { Cell } \\
\text { technology }\end{array}$ & $\begin{array}{l}\text { Cell } \\
\text { source }\end{array}$ & Host & $\begin{array}{l}\text { Vivo, ex } \\
\text { vivo }\end{array}$ & $\begin{array}{l}\text { Transplantation } \\
\text { site }\end{array}$ & $\begin{array}{l}\text { IOP } \\
\text { normalization }\end{array}$ \\
\hline Du, Yun, Yang, Schuman & 2013 & TMSCs & Human & Mice & Vivo & Anterior chamber & + \\
\hline Abu-Hassan, Li, Ryan, Acott, Kelley & 2015 & iPSC-TM & $\begin{array}{l}\text { Porcine- } \\
\text { Human }\end{array}$ & Human & Ex vivo & Anterior chamber & + \\
\hline Zhu, Gramlich, Laboissonniere, et al & 2016 & iPSC-TM & Mice & Mice & Vivo & Anterior chamber & + \\
\hline Zhu, Jain, Gramlich, Tucker, Sheffield, Kuehn & 2017 & iPSC-TM & Mice & Mice & Vivo & Anterior chamber & + \\
\hline
\end{tabular}


cultured human iPSC-TM were added back and allowed to attach and integrate into the anterior segments. ${ }^{57}$

\section{Conclusion}

In the eye, evidence reveals that there is a population of stem-like cells located in the transition area referred as Schwalbe's ring. In 1982, Raviola identified a population of unusual cells located just beneath the Schwalbe's line in the rhesus monkey. Not much attention was paid to Schwalbe's line cells until there was more evidence supporting the presence of stem/progenitor cells in this transition zone. The observation of an increase in TM cell division localized to the anterior non-filtering portion of the TM after ALT suggested the possible mechanisms of action is the repopulation of the TM by stimulating cell division. Recent progress in stem cell research provides an optimistic prospect on their use in regenerative medicine and tissue engineering. Specifically, advances in iPSCs and adult stem cells research raise hope for personalized cell replacement therapies.

Prospectively, it will be necessary to establish the safety profile and potential activity of TM stem cells transplantation through preclinical studies before moving to clinical trial in patients with glaucoma. Moreover, TM stem cells models will offer a new possibility for a better understanding of trabecular outflow physiology, glaucoma pathophysiology, and drug testing.

\section{Disclosure}

The authors report no conflicts of interest in this work.

\section{References}

1. Parrish RK. Reduction of intraocular pressure and glaucoma progression. Evidence-Based Eye Care. 2003;4(3):137-139.

2. Kass MA, Heuer DK, Higginbotham EJ, et al. The ocular hypertension treatment study: a randomized trial determines that topical ocular hypotensive medication delays or prevents the onset of primary open-angle glaucoma. Arch Ophthalmol. 2002;120(6):701-713.

3. Goel M, Picciani RG, Lee RK, Bhattacharya SK. Aqueous humor dynamics: a review. Open Ophthalmol J. 2010;4:52-59.

4. Stamer WD, Braakman ST, Zhou EH, et al. Biomechanics of Schlemm's canal endothelium and intraocular pressure reduction. Prog Retin Eye Res. 2015;44:86-98.

5. Fan BJ, Wiggs JL. Glaucoma: genes, phenotypes, and new directions for therapy. J Clin Invest. 2010;120(9):3064-3072.

6. Kopczynski CC, Epstein DL. Emerging trabecular outflow drugs. J Ocul Pharmacol Ther. 2014;30(2-3):85-87.

7. Hoy SM. Netarsudil ophthalmic solution $0.02 \%$ : first global approval. Drugs. 2018;78(3):389-396.

8. Fleischhauer JC, Mitchell CH, Stamer WD, Karl MO, Peterson-Yantorno $\mathrm{K}$, Civan MM. Common actions of adenosine receptor agonists in modulating human trabecular meshwork cell transport. J Membr Biol. 2003;193(2):121-136.

9. Villarreal G, Chatterjee A, Oh SS, Oh DJ, Rhee DJ. Pharmacological regulation of SPARC by lovastatin in human trabecular meshwork cells. Invest Ophthalmol Vis Sci. 2014;55(3):1657-1665.
10. Wang N, Chintala SK, Fini ME, Schuman JS. Activation of a tissuespecific stress response in the aqueous outflow pathway of the eye defines the glaucoma disease phenotype. Nat Med. 2001;7:304-309.

11. Scalinci SZ, Scorolli L, Corradetti G, et al. Potential role of intravitreal human placental stem cell implants in inhibiting progression of diabetic retinopathy in type 2 diabetes: neuroprotective growth factors in the vitreous. Clin Ophthalmol. 2011;5:691-696.

12. Takahashi K, Yamanaka S. Induction of pluripotent stem cells from mouse embryonic and adult fibroblast cultures by defined factors. Cell. 2006;126(4):663-676.

13. Stadtfeld M, Nagaya M, Utikal J, Weir G, Hochedlinger K. Induced pluripotent stem cells generated without viral integration. Science. 2008;322(5903):945-949.

14. Zhou H, Wu S, Joo JY, et al. Generation of induced pluripotent stem cells using recombinant proteins. Cell Stem Cell. 2009;4(6):581.

15. Lin T, Ambasudhan R, Yuan X, et al. A chemical platform for improved induction of human iPSCs. Nat Methods. 2009;6(11):805-808.

16. Zhu W, Jain A, Gramlich OW, Tucker BA, Sheffield VC, Kuehn MH. Restoration of aqueous humor outflow following transplantation of iPSC-derived trabecular meshwork cells in a transgenic mouse model of glaucoma. Invest Ophthalmol Vis Sci. 2017;58(4):2054-2062.

17. De Falco E, Scafetta G, Napoletano C, et al. A standardized laboratory and surgical method for in vitro culture isolation and expansion of primary human Tenon's fibroblasts. Cell Tissue Bank. 2013;14(2):277-287.

18. Scafetta G, Tricoli E, Siciliano C, et al. Suitability of human Tenon's fibroblasts as feeder cells for culturing human limbal epithelial stem cells. Stem Cell Rev. 2013;9(6):847-857.

19. Johnson M. What controls aqueous humour outflow resistance? Exp Eye Res. 2006;82(4):545-557.

20. Tamm ER. The trabecular meshwork outflow pathways: Structural and functional aspects. Exp Eye Res. 2009;88(4):648-65.

21. Barishak YR. Embryology of the eye and its adnexae. Dev Ophthalmol. 1992;24:1-142.

22. Cvekl A, Tamm ER. Anterior eye development and ocular mesenchyme: new insights from mouse models and human diseases. Bioessays. 2004;26(4):374-386.

23. Anderson DR. The development of the trabecular meshwork and its abnormality in primary infantile glaucoma. Trans Am Ophthalmol Soc. 1981;79:458-485.

24. Gehring WJ, Ikeo K. Pax 6: mastering eye morphogenesis and eye evolution. Trends Genet. 1999;15(9):371-377.

25. Chow RL, Lang RA. Early eye development in vertebrates. Annu Rev Cell Dev Biol. 2001;17:255-296.

26. Kitamura K, Miura H, Miyagawa-Tomita S, et al. Mouse PITX2 deficiency leads to anomalies of the ventral body wall, heart, extra- and periocular mesoderm and right pulmonary isomerism. Development. 1999;126(24):5749-5758.

27. Kidson SH, Kume T, Deng K, Winfrey V, Hogan BL. The forkhead/ winged-helix gene, MF1, is necessary for the normal development of the cornea and formation of the anterior chamber in the mouse eye. Dev Biol. 1999;211(2):306-322.

28. Evans AL, Gage PJ. Expression of the homeobox gene Pitx 2 in neural crest is required for optic stalk and ocular anterior segment development. Hum Mol Genet. 2005;14(22):3347-3359.

29. Sowden JC. Molecular and developmental mechanisms of anterior segment dysgenesis. Eye. 2007;21(10):1310-1318.

30. Liu P, Johnson RL. Lmx 1 b is required for murine trabecular meshwork formation and for maintenance of corneal transparency. Dev Dyn. 2010;239(8):2161-2171.

31. Chang B, Smith RS, Peters M, et al. Haploinsufficient Bmp4 ocular phenotypes include anterior segment dysgenesis with elevated intraocular pressure. BMC Genet. 2001;2:18.

32. Lütjen-Drecoll E. Functional morphology of the trabecular meshwork in primate eyes. Prog Retin Eye Res. 1999;18(1):91-119.

33. Stamer WD, Seftor RE, Snyder RW, Regan JW. Cultured human trabecular meshwork cells express aquaporin-1 water channels. Curr Eye Res. 1995;14(12):1095-1100. 
34. Chang IL, Elner G, Yue YJ, Cornicelli A, Kawa JE, Elner VM. Expression of modified low-density lipoprotein receptors by trabecular meshwork cells. Curr Eye Res. 1991;10(12):1101-1112.

35. Gasiorowski JZ, Russell P. Biological properties of trabecular meshwork cells. Exp Eye Res. 2009;88(4):671-675.

36. Polansky JR, Weinreb RN, Baxter JD, Alvarado J. Human trabecular cells. I. Establishment in tissue culture and growth characteristics. Invest Ophthalmol Vis Sci. 1979;18(10):1043-1049.

37. Wilson SE, Walker JW, Chwang EL, He YG. Hepatocyte growth factor, keratinocyte growth factor, their receptors, fibroblast growth factor receptor-2, and the cells of the cornea. Invest Ophthalmol Vis Sci. 1993;34(8):2544-2561.

38. Grierson I, Heathcote L, Hiscott P, Hogg P, Briggs M, Hagan S. Hepatocyte growth factor/scatter factor in the eye. Prog Retin Eye Res. 2000;19(6):779-802.

39. Tamura M, Iwamoto Y. The effect of platelet-derived growth factor on phagocytosis of cultured human trabecular cells. Exp Eye Res. 1989;48(6):761-770.

40. Ando K, Kaneko S, Matsumura M. Seichō inshi no eikyō baiyō buta Obashira-mō saibō no zōshoku [The effect of growth factors on the proliferation of cultured porcine trabecular meshwork cells]. Nihon Naika Gakkai Zasshi. 2004;93(4):705-710. Japanese.

41. Rohen JW, van der Zypen E. The phagocytic activity of the trabecular meshwork endothelium - an electron-microscopic study of the vervet (Cercopithecus aethiops). Albr von Graefes Arch Clin Exp Ophthalmol. 1968;175(2):143-160.

42. Joyce NC. Proliferative capacity of corneal endothelial cells. Exp Eye Res. 2012;95(1):16-23.

43. Chhunchha B, Singh P, Stamer WD, Singh DP. Prdx6 retards senescence and restores trabecular meshwork cell health by regulating reactive oxygen species. Cell Death Discov. 2017;3:17060.

44. Saccà SC, Izzotti A, Rossi P, Traverso C. Glaucomatous outflow pathway and oxidative stress. Exp Eye Res. 2007;84(3):389-399.

45. Alvarado J, Murphy C, Polansky J, Juster R. Age-related changes in trabecular meshwork cellularity. Invest Ophthalmol Vis Sci. 1981;21(5): $714-727$.
46. Grierson IAN, Howes RC. Age-related depletion of the cell population in the human trabecular meshwork. Nat Publ Gr. 1987;1(2):204-210.

47. Alvarado J, Murphy C, Juster R. Trabecular meshwork cellularity in primary open-angle glaucoma and nonglaucomatous normals. Ophthalmology. 1984;91(6):564-579.

48. Raviola G. Schwalbe line's cells: a new cell type in the trabecular meshwork of Macaca mulatta. Invest Ophthalmol Vis Sci. 1982;22(1):45-56.

49. Acott TS, Samples JR, Bradley JM, Bacon DR, Bylsma SS, van Buskirk EM. Trabecular repopulation by anterior trabecular meshwork cells after laser trabeculoplasty. Am J Ophthalmol. 1989;107(1):210-216.

50. Stein JD, Challa P. Mechanisms of action and efficacy of argon laser trabeculoplasty and selective laser trabeculoplasty. Curr Opin Ophthalmol. 2007;18(2):140-145.

51. Kelley MJ, Rose AY, Keller KE, Hessle H, Samples JR, Acott TS. Stem cells in the trabecular meshwork: present and future promises. Exp Eye Res. 2009;88(4):747-751.

52. Gonzalez P, Epstein DL, Luna C, Liton PB. Characterization of freefloating spheres from human trabecular meshwork (HTM) cell culture in vitro. Exp Eye Res. 2006;82(6):959-967.

53. Chamling X, Sluch VM, Zack DJ. The potential of human stem cells for the study and treatment of glaucoma. Invest Ophthalmol Vis Sci. 2016;57(5):ORSFi1-ORSFi6.

54. DuY, Roh DS, Mann MM, Funderburgh ML, Funderburgh JL, Schuman JS. Multipotent stem cells from trabecular meshwork become phagocytic TM cells. Invest Ophthalmol Vis Sci. 2012;53(3):1566-1575.

55. DuY, Yun H, Yang E, Schuman JS. Stem cells from trabecular meshwork home to TM tissue in vivo. Invest Ophthalmol Vis Sci. 2013;54(2): $1450-1459$.

56. Zhu W, Gramlich OW, Laboissonniere L, et al. Transplantation of iPSCderived TM cells rescues glaucoma phenotypes in vivo. Proc Natl Acad Sci USA. 2016;113(25):E3492-E3500.

57. Abu-Hassan DW, Li X, Ryan EI, Acott TS, Kelley MJ. Induced pluripotent stem cells restore function in a human cell loss model of open-angle glaucoma. Stem Cells. 2015;33(3):751-761.
Transplant Research and Risk Management

\section{Publish your work in this journal}

Transplant Research and Risk Management is an international, peerreviewed open access journal focusing on all aspects of transplantation and risk management to achieve optimal outcomes in the recipient improving survival and quality of life. The manuscript management system is completely online and includes a very quick and fair peer-review system,
Dovepress

which is all easy to use. Visit http://www.dovepress.com/testimonials.php to read real quotes from published authors. 